\title{
TITULADOR AUTOMÁTICO EM FLUXO-BATELADA UTILIZANDO UM HARDWARE DE CÓDIGO FONTE ABERTO ARDUINO
}

Fernanda S. C. Soares ${ }^{a}$, Rúbia E. C. R. Rodrigues ${ }^{a}$, Carla M. Bossu㣙, Márcio S. Soares ${ }^{a}$, Sidney X. dos Santos ${ }^{\text {a }}$, Gabriel O. Uebe ${ }^{\text {a }}$ e Alex A. Silva ${ }^{\text {a }}$

anstituto de Ciências Exatas e Tecnológicas, Universidade Federal de Viçosa, Campus Rio Paranaíba, 38810-000 Rio Paranaíba - MG, Brasil

Recebido em 16/07/2020; aceito em 15/10/2020; publicado na web em 11/11/2020

\begin{abstract}
AUTOMATIC TITROMETRIC METHOD IN FLOW-BATCH CONTROLLED BY AN ARDUINO OPEN SOURCE HARDWARE. This work describes the development of an automatic titrometric method in flow-batch with potentiometric detection using alternative and easily accessible materials. Arduino board and its modules, solenoid valves to control the flow rate, peristaltic pump to propel and suction fluids and tubes of inert material to connect the different parts of the Flow-Batch Analyser (FBA) were used. The use of solenoid valves controlled by microcontrollers proved to be efficient for controlling the flow in FBA systems, the correlations of their flow rates as a function of time showed good linearity with correlation coefficients (r) 0.9994 and 0.9997 for the valve 1 and valve 2, respectively, allowing correct addition of pre-established volumes. Accuracy was verified by comparing the results of the proposed method with the classic potentiometric titration with statistically evaluated by Student's $t$-test in $\mathrm{NaOH}$ with $\mathrm{HCl}$ and vinegar with $\mathrm{NaOH}$ titrations. Results confirmed the efficiency to use Arduino board and its modules and automatic titrometric method in flow-batch developed in this work allow the implementation of practical disciplines, such as potentiometric titration and flow analysis system in undergraduate courses, making these instruments more accessible, especially for the chemistry students.
\end{abstract}

Keywords: potentiometric titration; Arduino; flow-batch.

\section{INTRODUÇÃO}

O conceito de miniaturização-integração, na química, fundamentase na ideia da conectividade das diferentes etapas de um procedimento de análise, que minimiza ao máximo a intervenção humana, apresenta baixo consumo de reagentes e amostras, diminuição de resíduos gerados e uma alta frequência analítica. ${ }^{1,2}$

Os sistemas de análises por injeção em fluxo (Flow Injection Analysis - FIA) propostos em meados da década de 70 por Ruzicka e Hansen ${ }^{3}$ oferecem uma maneira flexível e simples de conectividade, parcial ou total, de diferentes etapas de uma análise química e pode ser definida como um processo de automatização de procedimentos analíticos, no qual a amostra em solução aquosa é introduzida em um fluido carregador que a transporta em direção a um detector. Durante o processo, a amostra pode receber reagentes, sofrer reações químicas e passar por etapas de separação. ${ }^{4}$ Segundo IUPAC (International Union of Pure and Applied Chemistry), os analisadores em fluxo são classificados conforme o processamento da amostra e/ou reagente (contínuo ou intermitente), tal como as características do fluxo (segmentado, não-segmentado ou monossegmentado). ${ }^{5}$ Assim, os analisadores apresentam diferentes classificações, dentre elas existem os analisadores em fluxo-batelada (Flow-Batch Analyser - FBA). ${ }^{6}$

O Analisador em Fluxo-Batelada foi proposto Honorato et al., como alternativa aos métodos existentes de analisadores automáticos em fluxo, como por exemplo, no desenvolvimento de uma titulação automática a qual opere com uma única solução padrão (titulante) sem a necessidade de curvas analíticas e que ocorre no interior de uma câmara de mistura. A câmara de mistura ou câmara reacional é o principal componente do analisador em fluxo-batelada, pois nela é possível realizar diversos procedimentos analíticos, tais como acondicionamento dos fluidos, diluições, método de adição padrão, pré-tratamento da amostra, preparo de soluções padrão e detecção

*e-mail: carla.bossu@gmail.com do analito. Também é possível obter melhores condições de misturas dos fluidos ao empregar o uso de uma barra magnética no interior da câmara de mistura, controlada através de um agitador magnético. ${ }^{8}$

Em síntese, os sistemas em fluxo-batelada oferecem uma instrumentação simples, de fácil operação, versáteis, flexíveis, apresentam procedimentos analíticos rápidos e precisos, com baixo consumo de reagentes e amostras, baixo custo por análise, alta frequência analítica, alta precisão e exatidão, baixa geração de resíduos, assim como menor contaminação e manipulação de amostras e reagentes. ${ }^{9}$ Suas características permitem a adaptação de um potenciômetro para medida do $\mathrm{pH}$ durante o processo de titulação.

A vantagem no uso de tituladores automáticos é o registro do sinal analítico a cada adição do titulante, obtendo-se assim uma curva de titulação, de maneira que o ponto final poderá ser determinado, mesmo nas situações em que o salto potenciométrico não é intenso. ${ }^{10-12} \mathrm{Nesse}$ caso, os métodos gráficos ou de linearização podem ser utilizados para identificar o ponto final, como por exemplo, métodos de Gran II, ${ }^{13}$ Sorensen, ${ }^{10,11}$ da derivada segunda,${ }^{14}$ entre outros.

O processo de automação é considerado o ato de apoiar qualquer sistema em computadores que vise substituir tarefas de trabalho humano e/ou que vise soluções rápidas e econômicas para as indústrias e serviços modernos. ${ }^{15}$ As plataformas de desenvolvimento baseadas em microcontroladores podem ser utilizadas em projetos de diversas áreas do conhecimento. ${ }^{2} \mathrm{O}$ microcontrolador pode ser entendido como a incorporação de um microprocessador, de sistemas de temporização, de aquisição e de comunicação em um mesmo circuito integrado. Um exemplo de plataforma de desenvolvimento, baseado em microcontrolador, largamente utilizado atualmente é o Arduino ${ }^{16-19}$ que faz parte do conceito de hardware e software livre e está aberto para uso e contribuição por toda sociedade.

Neste contexto, conceitos de métodos titulométricos clássicos empregados nas aulas de laboratório do curso de graduação em química foram reformulados e automatizados, conciliando conhecimentos de física, eletrônica e química, a fim de desenvolver 
um método titulométrico automático em fluxo-batelada com detecção potenciométrica utilizando materiais alternativos e de fácil acesso, a fim de ser empregado nas aulas de laboratórios de química analítica e utilizado pelos estudantes de graduação. Dessa forma, utilizou-se o módulo microcontrolado Arduino e os módulos para o controle das válvulas solenoides para controle da vazão do fluxo, bomba peristáltica para propulsionar e succionar os fluidos, além de tubos de material inerte para conectar as diferentes partes do sistema FBA.

\section{PARTE EXPERIMENTAL}

\section{Reagentes e soluções}

Todas as soluções foram preparadas utilizando reagentes de grau analítico e água deionizada com resistividade $\geq 18 \mathrm{M} \Omega \mathrm{cm}$ produzida em sistema Milli-Q ${ }^{\circledR}$ (Millipore, Bedford, MA, USA). Soluções previamente padronizados de $\mathrm{HCl}$ (Vetec Química Fina Ltda., Brasil) 0,1 mol L-1, fator de correção 0,98 e $\mathrm{NaOH}$ (Vetec Química Fina Ltda., Brasil) 0,1 mol L-1 , fator de correção 1,00, foram utilizadas nas titulações de ácido forte-base forte. Além disso, vinagre comercial e $\mathrm{NaOH}$ (Vetec Química Fina Ltda., Brasil) 0,05 $\mathrm{mol} \mathrm{L}^{-1}$, fator de correção 1,00 foram usados para a realização da determinação do teor de ácido acético. Como indicador ácido-base foi utilizado o reagente fenolftaleína para todas as titulações.

\section{Instrumentação}

Neste trabalho, as titulações potenciométricas clássicas de base forte com ácido forte e de vinagre com base forte foram utilizadas para comparação dos resultados obtidos. Um pHmetro (E-201C) comercial constituído de eletrodo indicador de vidro com eletrodo de referência de $\mathrm{Ag} / \mathrm{AgCl}$ foi utilizado para os métodos clássicos e juntamente com Arduino.

\section{Titulação de base forte com ácido forte}

Realizou-se titulações utilizando protótipo do titulador automático em fluxo-batelada com detecção potenciométrica proposto neste trabalho, empregando solução de $\mathrm{NaOH} 0,1 \mathrm{~mol} \mathrm{~L}^{-1}$ como titulado, que foi adicionado primeiramente à câmara reacional através da abertura da válvula 1 durante $30 \mathrm{~s}$. O volume correspondente obtido para esse tempo de abertura foi de $16,17 \mathrm{~mL}$, calculado com base nos estudos de vazão das válvulas que serão demonstrados a seguir. Após o enchimento da câmara reacional, adicionou-se uma gota do indicador fenolftaleína na solução a fim de se monitorar o esmaecimento da cor em função da adição de titulante $(\mathrm{HCl})$. Em seguida, a válvula 2 foi aberta para adição de pequenas quantidades de $\mathrm{HCl} 0,1 \mathrm{~mol} \mathrm{~L}^{-1}$ à câmara reacional. $\mathrm{O}$ pH durante processo de titulação foi monitorado em função do volume $(\mathrm{mL})$ de $\mathrm{HCl}$ adicionado e uma curva de titulação foi obtida em tempo real a partir de uma tabela no Excel com o programa desenvolvido.

Em seguida, realizou-se titulações utilizando método convencional. Para tal, mediu-se um volume de $17 \mathrm{~mL}$ de $\mathrm{NaOH} 0,1 \mathrm{~mol} \mathrm{~L}^{-1}$, a este foi adicionado uma gota do indicador ácido-base fenolftaleína e então titulou-se com o auxílio de uma bureta contendo $\mathrm{HCl} \mathrm{0,1} \mathrm{mol} \mathrm{L}^{-1}$. Todos os experimentos foram feitos em triplicata.

\section{Determinação do teor de ácido acético em vinagre}

O mesmo preparo da amostra de vinagre foi utilizado no método proposto e na titulação clássica. Uma alíquota de $100 \mathrm{~mL}$ da amostra de vinagre foi transferida para um balão de $500 \mathrm{~mL}$ e o volume completado com água destilada. Após homogeneização desta última solução, pipetaram-se $30 \mathrm{~mL}$ da solução preparada para um frasco erlenmeyer, adicionando-se em seguida $30 \mathrm{~mL}$ de água destilada e foram usados $12 \mathrm{~mL}$ dessa última solução diluída 1:1 para a realização das titulações.

Para o protótipo do titulador automático em fluxo-batelada com detecção potenciométrica proposto neste trabalho, a amostra de vinagre preparado foi adicionada primeiramente à câmara reacional através da abertura da válvula 1 durante $15 \mathrm{~s}$. Esse tempo de abertura da válvula 1 foi reduzido de $30 \mathrm{~s}$ para $15 \mathrm{~s}$ pois ocorreu enchimento da câmera reacional do equipamento antes de atingir o ponto de equivalência, assim, reduziu-se o volume de ácido a ser titulado para $12 \mathrm{~mL}$. Após o enchimento da câmara reacional, adicionaram-se duas a três gotas do indicador fenolftaleína na solução e a válvula 2 foi aberta para adição de pequenas quantidades de $\mathrm{NaOH} 0,05 \mathrm{~mol} \mathrm{~L}^{-1}$ (titulante) à câmara reacional. $\mathrm{O}$ pH durante processo de titulação foi monitorado em função do volume $(\mathrm{mL})$ de $\mathrm{NaOH}$ adicionado e uma curva de titulação foi obtida em tempo real a partir de uma tabela no Excel com o programa desenvolvido.

Em seguida, realizaram-se titulações utilizando método clássico e mediu-se um volume de $12 \mathrm{~mL}$ da amostra preparada de vinagre, a ela adicionaram-se duas a três gotas do indicador ácido-base fenolftaleína e então titulou-se com o auxílio de uma bureta contendo $\mathrm{NaOH} 0,05 \mathrm{~mol} \mathrm{~L}^{-1}$

\section{Construção do titulador automático em fluxo-batelada com detecção potenciométrica}

O titulador automático em fluxo-batelada com detecção potenciométrica proposto neste trabalho foi desenvolvido utilizando material alternativo e de fácil aquisição. A Figura 1 mostra o diagrama esquemático do titulador automático em fluxo-batelada, o circuito eletrônico, o agitador magnético construído e o protótipo do titulador automático em fluxo-batelada com detecção potenciométrica.

\section{Analisador em fluxo-batelada (FBA)}

Na Figura 1 (a), a construção do FBA foi realizada utilizando tubos de material inerte conectados aos recipientes (1 e 2), os quais contém as soluções a serem utilizadas no processo de titulação. As soluções foram propulsionadas e succionadas por uma bomba peristáltica previamente construída também com materiais alternativos e de baixo custo (5), conforme descrito por Soares et al. ${ }^{17}$

De acordo com a Figura 1 (a), a bomba peristáltica (5) propulsiona os fluidos em direção às válvulas solenoides (6) e (7) (Modelo $90^{\circ}$ 3/4" x Mangueira 3/8 12V DC, 2 vias - entrada e saída), denominadas como válvulas 1 e 2 respectivamente, as quais controlam a vazão em seus respectivos canais. As válvulas estão conectadas a uma câmara reacional (10), na qual ocorre o processo de titulação, que consiste na adição prévia de titulado, pela abertura da válvula 1 durante $30 \mathrm{~s}$ seguida da adição de pequenos incrementos de volume de titulante, pela abertura da válvula 2 , que se mantém aberta durante $0,2 \mathrm{~s}$ para adição do titulante e fechada por $3 \mathrm{~s}$ para homogeneização da mistura e leitura do pH. O sistema é mantido sob agitação constante por meio de um agitador magnético, também construído com materiais alternativos, a fim de se obter uma maior homogeneidade da solução. A câmara reacional (10) está acoplada a um detector (11), eletrodo de $\mathrm{pH}$, que informa o estágio em que se encontra o processo de titulação. As informações de volume de titulante adicionado e pH são transmitidas instantaneamente para o computador onde é construído um gráfico de $\mathrm{pH}$ versus volume de titulante.

Ao fim do processo de titulação inicia-se o processo de lavagem da câmara reacional através da abertura da válvula solenoide 3 (8), 


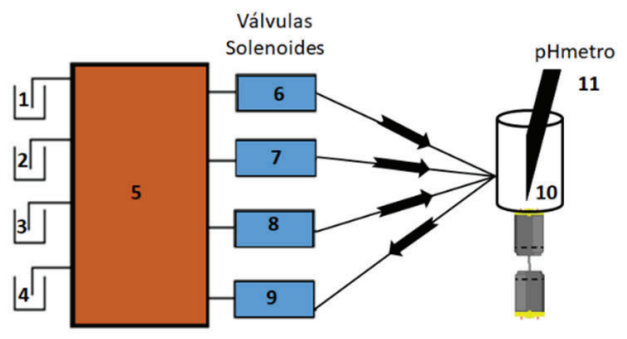

(a)

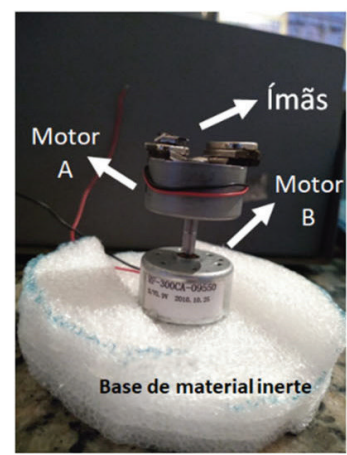

(c)

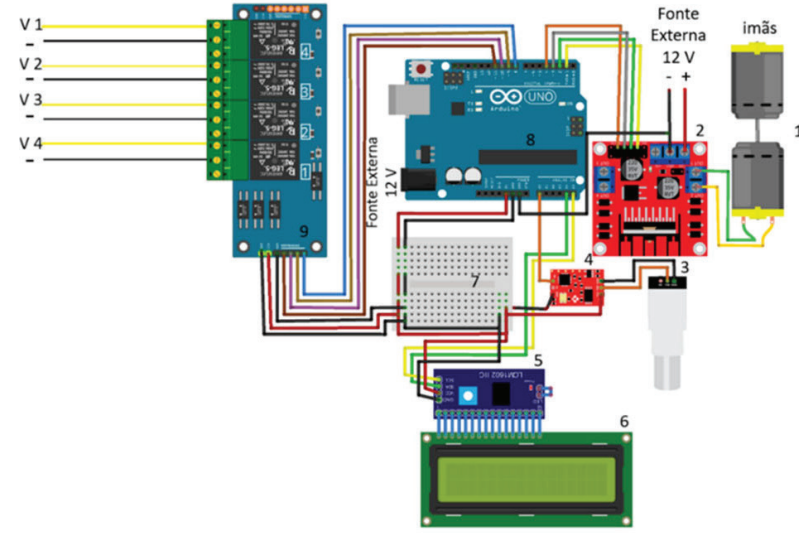

(b)

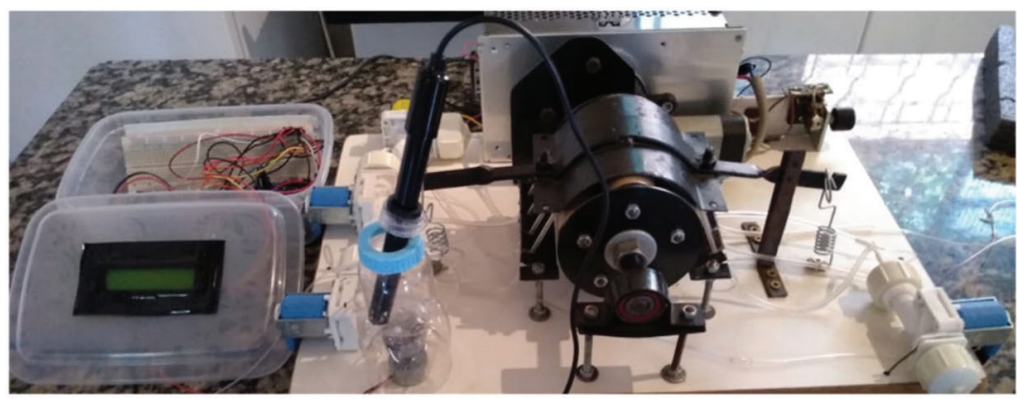

(d)

Figura 1. (a) Diagrama esquemático do titulador automático em fluxo-batelada (1) ácido, (2) base, (3) água, (4) descarte, (5) bomba peristáltica, (6) válvula 1, (7) válvula 2, (8) válvula 3, (9) válvula 4, (10) misturador e (11) detector; (b) Circuito eletrônico utilizado no desenvolvimento do titulador automático (1) Motores DC, (2) Ponte H, (3) Pino pHmetro, (4) Módulo pHmetro, (5) Módulo IC, (6) Monitor LCD, (7) Protoboard, (8) Arduino UNO e (9) Módulo Relé; (c) Agitador magnético construído; (d) Protótipo do titulador automático em fluxo-batelada com detecção potenciométrica

a qual está conectada a um recipiente contendo água (3), que é propulsionada pela bomba peristáltica até a câmara reacional (10). Após um tempo de abertura de $45 \mathrm{~s}$, a válvula 3 se fecha e então a válvula solenoide 4 (9) se abre para que a água da lavagem seja aspirada através de uma conexão contrária as demais, feita na bomba peristáltica em direção ao descarte (4).

Foi necessária uma adaptação nas entradas e saídas das válvulas solenoides a fim de diminuir o diâmetro das mesmas para conexão dos tubos de material inerte de $8 \mathrm{~mm}$. Para isso utilizaram-se tampas de $3 / 4$ de polegada para a entrada das válvulas 1,2 e 3 ; e tampas de $1 / 2$ polegada para a válvula 4 , nos quais foram realizados furos com diâmetro adequado para o encaixe dos tubos utilizados no FBA que foram fixados com silicone. Para saída das válvulas 1, 2 e 3 não foi possível encontrar tampas de tamanho adequado pois as mesmas possuíam diâmetro menor que $1 / 2$ polegada, portanto, adaptaramse tampas de embalagens de detergente comercial. As tampas de detergentes utilizadas foram coladas a partir de sua base à saída da válvula solenoide com adesivo a base de cianoacrilato e adesivo termoplástico composto de resina de EVA (copolímero de etileno e acetato de vinila) e resina taquificante (cola quente). A válvula 4 possuía tanto a entrada como a saída com $1 \frac{1}{2}$ polegada de diâmetro, o que possibilitou a utilização de uma tampa de $1 / 2$ polegada também em sua saída.

\section{Câmara reacional}

A câmara reacional (misturador) foi construída utilizandose um recipiente de material inerte de acrílico transparente com $3,5 \mathrm{~cm}$ de diâmetro interno e externo, com volume mínimo que permite a detecção do sinal, ou seja, quando a solução encosta na ponta do sensor do pHmetro, de aproximadamente $9,5 \mathrm{~mL}$ e com volume total em torno de $25 \mathrm{~mL}$. A altura da câmara reacional é de aproximadamente $5 \mathrm{~cm}$, possuindo um orifício para acoplamento do detector. Foram conectados a esta câmara três canais de entrada na parte superior e um canal de saída na parte inferior.

\section{Agitador magnético}

Para homogeneizar a mistura titulante/titulado na câmara reacional foi construído um agitador magnético alternativo. Trata-se de um equipamento compacto e que pode ser controlado, juntamente com os outros componentes do FBA, pela placa Arduino (Arduino board) que é uma placa de prototipagem que possui um microcontrolador. Foram utilizados dois motores DC acoplados entre si utilizando um tubo de caneta como eixo central. Ao motor A, foram fixados ímãs, que proporcionam um campo magnético rotativo capaz de movimentar uma barra magnética, que permanece dentro da câmara. E o motor B foi fixado a uma base de material inerte e conectado à placa Arduino (Figura 1 (c)). A função do motor B (inferior) é fazer o motor A (superior) girar, por isso os dois são conectados pelo eixo de rotação (tubo de caneta). A função do motor A, é simplesmente encaixar os ímãs que induzem a agitação magnética a partir da rotação do motor B.

Para acoplar o agitador magnético construído na placa Arduino foi necessária a utilização de um módulo eletrônico denominado ponte $\mathrm{H}$ (Figura 1 (b)). Isso devido à corrente demandada pelo motor ser maior que àquela fornecida pelas portas do Arduino. Assim, o motor é alimentado por uma fonte externa e a placa Arduino é utilizado somente para controlar sua rotação. A ponte $\mathrm{H}$ consiste em uma etapa de potência para o fornecimento da tensão necessária para o funcionamento do motor. 


\section{Detector}

Para o monitoramento do curso da reação foi utilizado um sensor de $\mathrm{pH}$ (E-201C) acoplado à câmara reacional. O mesmo possui um módulo de pH (DIY MORE PH-4502C) compatível com a placa Arduino para aquisição dos valores de $\mathrm{pH}$ em função do volume de titulante adicionado à solução em análise. $\mathrm{O}$ sensor funciona como um eletrodo de $\mathrm{pH}$ convencional, sendo o eletrodo indicador de vidro combinado com o eletrodo de referência de $\mathrm{Ag} / \mathrm{AgCl}$.

\section{O circuito eletrônico}

Para a construção do protótipo do titulador automático em fluxo-batelada com detecção potenciométrica utilizou-se o circuito eletrônico representado na Figura 1 (b). Um monitor Liquid Crystal Display (LCD) foi utilizado para acompanhar o estágio da titulação, fornecendo os valores medidos de $\mathrm{pH}$ a cada segundo e informando qual válvula se encontra aberta no momento. Para a conexão do monitor LCD ao microcontrolador foi utilizado um módulo chamado $\mathrm{I}^{2} \mathrm{C}$, que diminui a quantidade de fios conectados diretamente na placa do Arduino, a fim de deixar livres os terminais para a conexão dos demais componentes do titulador.

A placa Arduino é alimentada por uma fonte de $12 \mathrm{~V}$ e redistribui uma corrente de 5 A para os componentes com a função de controlar o funcionamento de cada componente do circuito. Uma protoboard foi necessária para alimentar os módulos utilizados com a corrente fornecida pelo Arduino (5 A) e para conectar ao ground (GND), ponto neutro que exerce função de blindagem contra interferência e ruídos elétricos.

O módulo Relé utilizado apresenta quatro canais que controlam a abertura e o fechamento de cada uma das válvulas solenoides utilizadas a fim de controlar o fluxo de solução pelo caminho analítico.

Todos os componentes foram conectados utilizando-se fios jumpers, com exceção das conexões feitas entre os canais do módulo Relé e as válvulas solenoides, nos quais foi necessária a utilização de fios de cobre com diâmetro maior do que $3 \mathrm{~mm}$.

Cada válvula solenoide possui dois pinos de conexão, a um deles foi conectado o positivo de uma fonte de $12 \mathrm{~V}$ e ao outro pino foi conectado a primeira porta do canal do módulo Relé. Ao segundo canal do módulo Relé foi conectado o negativo da fonte de $12 \mathrm{~V}$ e o módulo Relé por sua vez foi conectado ao Arduino.

\section{O código sketch}

Para programação da plataforma de prototipagem eletrônica Arduino foi utilizada uma lógica de programação. A placa Arduino carrega os dados das bibliotecas no sistema, lê as variáveis declaradas para os dispositivos e define os pinos relacionados a cada um deles. Na sequência, o monitor LCD e a comunicação serial entre os dados obtidos pelo Arduino e o Excel são preparados para inicialização. Logo em seguida, o motor DC é acionado para o funcionamento do agitador automático e a válvula 1 é aberta durante $30 \mathrm{~s}$ para adição de $17 \mathrm{~mL}$ de titulado à câmara reacional. Passado o tempo estabelecido, a válvula 1 é fechada.

Então ocorre a inicialização do processo em loop, ou seja, os processos que se repetem continuamente. A princípio são acionadas as funções para diminuição do ruído eletrônico inerente à quantificação do valor do $\mathrm{pH}$ pelo sensor e posteriormente as funções referentes à conversão dos valores medidos pelo sensor para a escala de $\mathrm{pH}$. Em seguida são fornecidas as funções para medida do volume de titulante adicionado em função do tempo de titulação. Esses dados são fornecidos a uma tabela no Excel para a construção de um gráfico de $\mathrm{pH}$ versus volume de titulante e também para o monitor LCD.

Logo em seguida, algumas funções definem o estado da válvula 2 em função do $\mathrm{pH}$, a qual fica aberta durante $0,2 \mathrm{~s}$ e fechada durante 30 s para adição de pequenos incrementos de volume de titulante na câmara reacional. A válvula 2 fecha quando um valor de pH préestabelecido é atingido. Após isso, outras funções definem a abertura da válvula 4 durante $60 \mathrm{~s}$ para o esvaziamento da câmara reacional. Em seguida, há a etapa de limpeza da câmara reacional, que consiste na abertura da válvula 3 durante 30 s para adição de água e após seu fechamento, a válvula 4 é novamente aberta para o esvaziamento da câmara reacional, tornando-a apta a um novo processo de titulação.

Por fim, algumas funções estabelecem a ordem da aquisição dos dados pelo programa Arduino Excel, o que permite a construção do gráfico de $\mathrm{pH}$ em função do volume de titulante.

\section{Comunicação de dados}

A comunicação de dados entre o Arduino e periféricos ocorre de duas maneiras diferentes: pelo display $\mathrm{LCD}$ via módulo $\mathrm{I}^{2} \mathrm{C}$ e pela comunicação serial com o notebook usando cabo USB.

A comunicação direta do Arduino com um display LCD requer pelo menos seis portas digitais para a conexão. Portanto, optou-se pelo uso do módulo $\mathrm{I}^{2} \mathrm{C}$, que necessita apenas de duas portas do Arduino, economizando as demais para a ligação dos demais componentes. Para tanto, são usados o pino analógico 4 (SDA) e o pino analógico 5 (SCL), que formam a interface de comunicação $\mathrm{I}^{2} \mathrm{C}$. Para controlar esse módulo $\mathrm{I}^{2} \mathrm{C}$, utilizou-se a biblioteca LiquidCrystal_I ${ }^{2} \mathrm{C}$.

A comunicação serial com o notebook usando cabo USB foi feita pelo Arduino Excel, ${ }^{17}$ que é uma ferramenta adicional de aquisição de dados de microcontroladores para Microsoft Excel. Para coletar os dados do experimento, deve-se abrir a planilha Arduino_Excel_21. $x l s m$, que contém uma macro que permite salvar os dados do USB no Excel, escolher a porta USB à qual o Arduino está conectado e clicar no botão Connect. Além da coleta de dados para a avaliação do desempenho do titulador automático proposto, o gráfico é obtido em tempo real. A Figura 1 (d) mostra o instrumento proposto finalizado e seus componentes.

\section{RESULTADOS E DISCUSSÃO}

A otimização dos volumes transferidos pelas válvulas foi realizada com a bomba peristáltica em velocidade máxima, uma vez que o potenciômetro da fonte de $12 \mathrm{~V}$ que alimenta o motor de vidro elétrico automotivo não apresenta escala graduada. Assim, atribuiuse a velocidade máxima da bomba peristáltica como referência para estes estudos e o tempo de abertura das válvulas é que determina o volume transferido.

Cada válvula solenoide possibilita que diferentes quantidades de fluido passem entre seus caminhos de entrada e saída, assim sendo, cada válvula encaminha um volume de líquido diferente para a câmara de mistura durante um dado intervalo de tempo.

Por essas razões, é essencial o estudo do fluxo para as válvulas solenoides. Para tanto, foram realizados estudos de fluxo apenas para as válvulas 1 e 2, já que essas são as responsáveis pela adição do titulado e do titulante na câmara reacional, respectivamente. Dessa forma, tornou-se necessário saber os volumes exatos liberados pelas válvulas para a realização dos cálculos referentes ao processo de titulação.

Os experimentos foram realizados mantendo-se a bomba peristáltica com velocidade constante por todo percurso analítico, ou seja, sem alterar o potenciômetro. No final do percurso analítico, após a saída das válvulas solenoides foi colocada uma proveta de $25 \mathrm{~mL}$, esperou-se completar os $5 \mathrm{~mL}$ da proveta, observando o menisco, então marcou-se o tempo com o auxílio de um cronômetro. A cada $5 \mathrm{~mL}$ anotou-se o tempo transcorrido. É importante mencionar que os volumes medidos pela proveta utilizada foram previamente conferidos utilizando uma balança analítica, a fim de se obter medidas mais precisas. 
Com esses valores calculou-se o fluxo em velocidade máxima, construiu-se um gráfico de volume $(\mathrm{mL})$ versus tempo em segundos (s) a fim de verificar a linearidade na vazão da válvula 1 e o fluxo médio conforme apresentado na Tabela 1. Pode-se observar uma boa linearidade e um bom coeficiente de correlação (r) e através da equação da reta calculou-se o volume liberado pela válvula 1 no tempo de $30 \mathrm{~s}$, tempo pré-estabelecido pelo programa como o tempo de abertura para o enchimento da câmara reacional com titulado, obtendo-se um volume de $16,17 \mathrm{~mL}$, e a faixa dinâmica de operação para a válvula 1 , isso é, a vazão mínima e máxima da curva de calibração apresentou volumes entre 5 e $20 \mathrm{~mL}$.

Um estudo também foi realizado medindo-se diretamente o volume transferido desde a abertura da válvula 1 até o seu fechamento, a fim de se verificar a fluxo real. Esse experimento foi realizado em triplicata utilizando-se uma proveta de $50 \mathrm{~mL}$ e um cronômetro, apresentando um volume em torno de $17 \mathrm{~mL}$. Através dos resultados obtidos, foi possível notar a similaridade entre o valor teórico de volume, obtido pela equação da reta, com o valor real através da medida direta do volume da solução liberada pela válvula 1 em $30 \mathrm{~s}$.

O mesmo experimento foi realizado para o cálculo da vazão da válvula 2 (Tabela 1). Nesse caso foi utilizada uma proveta de $10 \mathrm{~mL}$ a fim de se obter maior precisão dos volumes liberados pela válvula 2 devido a seu intervalo de tempo menor e, portanto, menor fluxo. Com esses valores, calculou-se o fluxo médio em velocidade máxima e construiu-se um gráfico de volume (mL) versus tempo (s), a fim de verificar a linearidade na vazão da válvula 2 . Na Tabela 1 estão apresentados o fluxo médio, a equação da reta e linearidade através do coeficiente de correlação (r) para a válvula 2 . A equação da reta obtida foi utilizada no programa para que a vazão da válvula 2 fosse calculada automaticamente em função do seu tempo de abertura, apresentando um volume teórico de $15,75 \mathrm{~mL}$ e um volume real de $16 \mathrm{~mL}$. E a faixa dinâmica de operação da curva de calibração foi entre 1 e $7 \mathrm{~mL}$ para a válvula 2. É importante mencionar que a válvula 1 abre e fecha uma única vez, já a válvula 2 funciona continuamente abrindo e fechando várias vezes, ocorrendo a possibilidade de acumular erros.
A fim de validar o método proposto, curvas de titulação, primeira e segunda derivadas foram obtidas através de uma planilha do Excel previamente desenvolvida. ${ }^{20}$ Tendo em vista que o conceito de derivada é uma diferença que relaciona a variação entre dois pontos, a primeira derivada nos fornece os valores onde ocorrem as maiores variações entre os resultados. Na Figura 2, observa-se a curva de titulação (1), o ponto que atinge o pico mais alto e coincide com os pontos máximos da relação $\mathrm{pH}$ versus volume, permitindo que se identifique o valor do $\mathrm{pH}$ no ponto final (2) e as curvas de segunda derivada (3) para o titulador automático em fluxo-batelada com detecção potenciométrica proposto e o métodos convencional para a titulação de $\mathrm{NaOH}$ com $\mathrm{HCl}$. As curvas de segunda derivada revelam o ponto final da titulação, fundamentando-se no conceito matemático de que a segunda derivada indica a mudança de sentido da concavidade de uma dada curva. A partir dessas curvas, utilizou-se o método dos mínimos quadrados para determinar o valor dos volumes finais nas titulações. Nas Figuras 2 (a) e 2 (b) estão representadas as curvas obtidas para uma das três replicatas, apresentando sempre perfis semelhantes.

Na Figura 3, observa-se a curva de titulação (1), os valores do pH no ponto final através das curvas de primeira derivada (2) e as curvas de segunda derivada (3) para o titulador automático em fluxo-batelada com detecção potenciométrica proposto e o métodos convencional para a titulação de vinagre com $\mathrm{NaOH}$. Nas Figuras 3 (a) e 3 (b) estão representadas as curvas obtidas para uma das três replicatas, apresentando sempre perfis semelhantes.

A fim de avaliar a exatidão do método proposto comparou-se os valores de $\mathrm{pH}$ e os volumes no ponto final com o método convencional conforme demonstrado na Tabela 2.

Os resultados obtidos para valores de $\mathrm{pH}$ e volumes no ponto final da titulação para o método proposto e para o método convencional foram comparados e não se mostraram estatisticamente diferentes ao nível de $95 \%$ de confiança (teste $t$-Student pareado). O titulador automático em fluxo-batelada com detecção potenciométrica proposto apresentou boa exatidão e precisão quando comparado

Tabela 1. Controle do fluxo em relação ao tempo de funcionamento da válvula 1 e da válvula 2

\begin{tabular}{lcccc}
\hline & Equação da reta & $\mathrm{R}^{2}$ & Faixa dinâmica de operação $(\mathrm{mL})$ & Fluxo médio $\left(\mathrm{mL} \mathrm{s} \mathrm{s}^{-1}\right)$ \\
\hline Válvula 1 & $\mathrm{y}=0,5353 \mathrm{x}+0,1098$ & 0,9994 & 5 a 20 & $0,55 \pm 0,02$ \\
Válvula 2 & $\mathrm{y}=0,0569 \mathrm{x}-0,0132$ & 0,9997 & 1 a 7 & $0,06 \pm 0,004$ \\
\hline
\end{tabular}
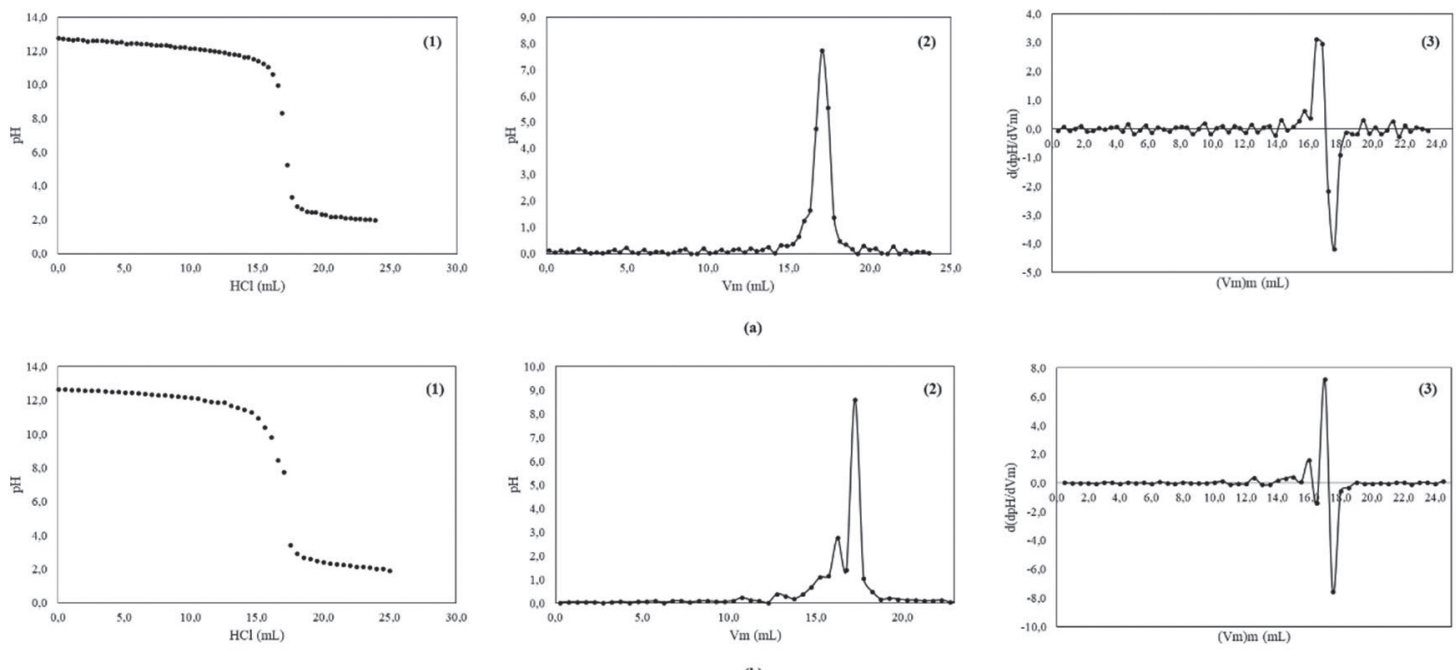

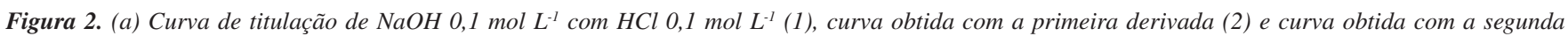
derivada (3) para o protótipo de titulador automático em fluxo-batelada com detecção potenciométrica; (b) Curva de titulação de NaOH 0,1 mol $L^{-1}$ com $\mathrm{HCl}$ 0,1 mol L ${ }^{-1}$ (1), curva obtida com a primeira derivada (2) e curva obtida com a segunda derivada (3) para o método convencional 

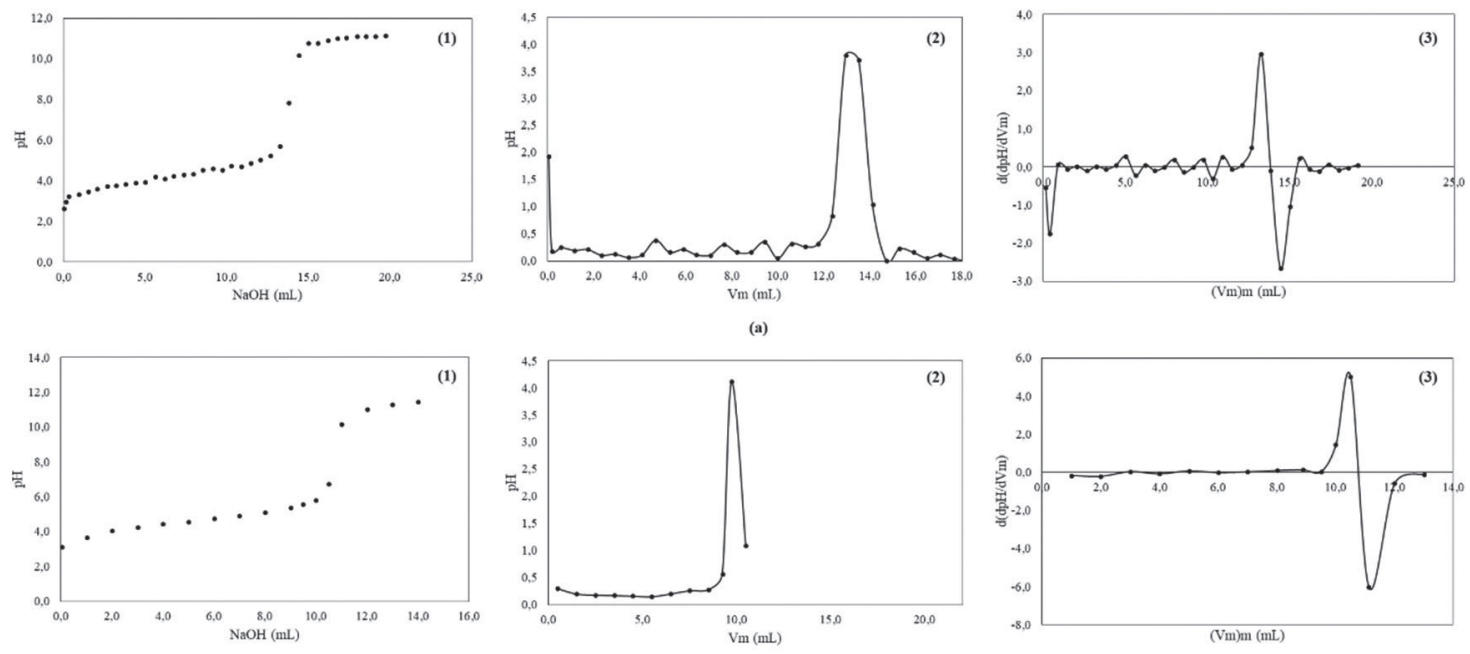

Figura 3. (a) Curva de titulação de vinagre com $\mathrm{NaOH} 0,05 \mathrm{~mol} \mathrm{~L}^{-1}$ (1), curva obtida com a primeira derivada (2) e curva obtida com a segunda derivada (3) para o protótipo de titulador automático em fluxo-batelada com detecção potenciométrica; (b) Curva de titulação de vinagre com NaOH 0,05 mol $L^{-1}$ (1), curva obtida com a primeira derivada (2) e curva obtida com a segunda derivada (3) para o método convencional

Tabela 2. Valores de $\mathrm{pH}$ e dos volumes no ponto final obtidos $(n=3)$ pela titulação clássica e pelo método proposto de titulador automatico em fluxo-batelada com detecção potenciométrica para as titulações de $\mathrm{NaOH}$ com $\mathrm{HCl}$ e de vinagre comercial com $\mathrm{NaOH}$. Coeficiente de variação (CV, \%)

\begin{tabular}{lcccc}
\hline Titulações & $\mathrm{pH}$ & $\mathrm{CV}(\%)$ & Ponto final $(\mathrm{mL})$ & $\mathrm{CV}(\%)$ \\
\hline Clássica $(\mathrm{NaOH} / \mathrm{HCl})$ & $8,54 \pm 0,08$ & 0,94 & $17,10 \pm 0,15$ & 0,90 \\
Fluxo-batelada $(\mathrm{NaOH} / \mathrm{HCl})$ & $8,17 \pm 0,05(2,71)$ & 0,61 & $17,20 \pm 0,40(0,70)$ & 2,33 \\
Clássica (Vinagre/NaOH) & $4,20 \pm 0,10$ & 2,20 & $11,41 \pm 0,52$ & 4,59 \\
Fluxo-batelada $($ Vinagre/NaOH) & $3,50 \pm 0,20(3,34)$ & 6,0 & $13,43 \pm 0,67(2,93)$ & 4,97 \\
\hline
\end{tabular}

Valor de $t$ pareado com $95 \%$ de confiança $=4,30 ;()=$ valor de $t$ calculado.

com a titulação clássica e os valores de coeficiente de variação (CV) mostrados na Tabela 2 estão concordantes com os valores aceitáveis na literatura. ${ }^{21}$

Além disso, comparou-se os valores em porcentagem do teor de ácido acético presente no vinagre comercial que se apresenta em torno de $4 \%$ com os valores obtidos pelo titulador automático em fluxo-batelada com detecção potenciométrica proposto e os resultados obtidos foram de 3,6 \pm 0,2\% para o teor de acidez e recuperação de $91 \pm 5 \%$ em relação ao valor de referência (4\%) do vinagre comercial. Com base no resultado obtido do teor de ácido acético para o método proposto, comparando com o valor de referência, foi realizado o teste $t$-Student não pareado e os resultados não apresentaram diferenças significativas a $95 \%$ de confiança.

\section{CONCLUSÕES}

As médias de $\mathrm{pH}$ e de volumes no ponto final para as titulações de $\mathrm{NaOH}$ com $\mathrm{HCl}$ e de vinagre comercial com $\mathrm{NaOH}$ no método proposto e no método clássico foram estatisticamente equivalentes a 95\% de confiança, mostrando excelente desempenho do titulador automático em fluxo-batelada com detecção potenciométrica utilizando materiais alternativos e de fácil acesso.

O emprego de válvulas solenoides, controladas por microcontroladores, mostrou-se uma alternativa eficiente para o controle do fluxo de soluções em FBA, permitindo uma adição correta de volumes pré-estabelecidos.

O programa Arduino Excel, utilizado em integração com o programa desenvolvido neste trabalho para comunicação dos dados, demonstrou bom funcionamento e possibilitou a construção das curvas de titulação em tempo real durante as análises realizadas. A utilização do módulo microcontrolado Arduino e os módulos para o controle das válvulas demonstraram eficiência ao serem empregados na construção de instrumentos analíticos alternativos, mostrando ser promissor na integração com novos métodos e reformulação de equipamentos que possuem alto custo de mercado.

Para a construção do titulador automático em fluxo-batelada com detecção potenciométrica foram gastos aproximadamente US\$ 69,84 valor bem mais acessível do que um titulador automático comercial ( US\$9.050,00) e do que uma titulação convencional ( US\$ 247,00). É importante mencionar que o uso de um notebook ou computador para aquisição dos dados é recomendável pela praticidade, mas não é imprescindível para o funcionamento do titulador automático em fluxo-batelada com detecção potenciométrica proposto.

Além disso, o método titulométrico automático em fluxo-batelada com detecção potenciométrica desenvolvido neste trabalho pode ser utilizado em disciplinas práticas, como por exemplo em abordagens sobre assuntos relacionados às titulações potenciométricas e sistemas de análise por injeção em fluxo em cursos técnicos e de graduação em química.

\section{AGRADECIMENTOS}

Ao Programa Institucional de Bolsas de Apoio a Projetos de Ensino (PIBEN) da Universidade Federal de Viçosa Campus Rio Paranaíba.

\section{REFERÊNCIAS}

1. Ibañes-García, N.; Gonçalves, R. D. M.; Rocha, Z. M.; Góngora-Rubio, M. R.; Seabra, A. C.; Alonso, J.; Trends Anal. Chem. 2008, 27, 24. 
2. Steinsberger, T.; Kathriner, P.; Meier, P.; Mistretta, A.; Hauser, P. C.; Müller, B.; Sens. Actuators, B 2018, 255, 3558.

3. Ruzicka, J.; Hansen, E. H.; Anal. Chim. Acta 1975, 78, 145.

4. Reis, B. F.; Zagatto, E. A.; Jacinto, A. O.; Krug, F. J.; Bergamin, F. H.; Anal. Chim. Acta 1980, 119, 305.

5. Zagatto, E. A. G.; Van Staden, J. F.; Maniasso, N.; Stefan, R. I.; Marshall, G. D.; IUPAC 2002, 74, 585.

6. Zagatto, E. A. G.; Oliveira, C. C.; Collins, C. H.; Quim. Nova 1999, 22, 143.

7. Honorato, R. S.; Araújo, M. C. U.; Lima, R. A.; Zagatto, E. A.; Lapa, R. A.; Lima, J. L. C.; Anal. Chim. Acta 1999, 396, 91.

8. Andrade, S. A.; Andrade, S. I.; Martins, V. L.; Moreira, P. N.; Costa, D. J.; Lyra, W. S.; Araujo, M. C. U.; Microchem. J. 2013, 108, 151.

9. Zagatto, E. A. G.; Carneiro, J. M. T.; Vicente, S.; Fortes, P. R.; Santos, J. L. M.; Lima, J. L. F. C.; J. Anal. Chem. 2009, 64, 524.

10. Clesceri, L. S.; Greenberg, A. E.; Rice, E. W.; Standard Methods for the Examination of Water \& Wastewater, $20^{\text {th }}$ ed., Awwa/Apha: Boca Raton, 1998.
11. Larson, T. E.; Henley, L.; Anal. Chem. 1955, 27, 851.

12. Martins, J. V.; Souza, A. P. R.; Salles, M. O.; Serrano, S. H. P.; Quim. Nova 2010, 33, 755.

13. Gran, G.; Analyst 1952, 77, 661.

14. Harris, D. C.; Explorando a Química Analítica, $4^{\mathrm{a}}$ ed., LTC Editora: Rio de Janeiro, 2011.

15. Castrucci, P. B. L.; Bottura, C. P.; Enciclopédia de Automática, Vol. 1, Blucher: São Paulo, 2007.

16. Komogawa M. Y., Miranda J. C.; Quim. Nova 2013, 36, 1232.

17. Soares, F. S. C.; Vieira, A. L.; Soares, M. S.; Sant'Anna M. V.; Nascentes, R.; Bossu, C. M.; Quim. Nova 2018, 41, 1196.

18. Famularo, N.; Kholod, Y.; Kosenkov, D. J.; Chem. Educ. 2016, 93, 175.

19. Walkowiak, M.; Nehring, A.; J. Chem. Educ. 2016, 93, 778.

20. https://mundoquimico.com.br/derivada-primeira-e-derivada-segundaem-titulacoes/ acessada em outubro de 2020.

21. Taverniers, I.; Loose, M. D.; Bockstaele, E. V.; Trends Anal. Chem. 2004, 23, 535. 